\title{
Visual Properties of Striae Distensae of Chinese Women
}

\author{
Nkengne $\mathrm{A}^{1 *}$, Halimi $\mathbf{K}^{1}$, Vié $\mathbf{K}^{1}$,Seroul $\mathbf{P}^{2}$ and Trevisan $\mathrm{S}^{2}$ \\ ${ }^{1}$ Laboratoires Clarins, 5 rue Ampère, 95300 Pontoise, France \\ ${ }^{2}$ Newtone Technologies, 13 bis place Jules Ferry, 69006 Lyon, France
}

Submission: January 09, 2020; Published: January 23, 2020

*Corresponding author: Alex Nkengne, Laboratoires Clarins, 5 rue Ampère, 95300 Pontoise, France

\section{Abstract}

Background: Striae Distensae (SD) or stretch marks are manifestations of epidermal atrophy that would arise from a combination of hormonal factors and mechanical stretching and that are characterized by distinct microstructural features. The objective of this in vivo study was to investigate the biophysical properties of recent versus old SD in a Chinese population.

Methods: A cohort of 110 Chinese women, aged between 21 and 45 years old, were recruited. Fifty-five presented recent and inflamed SD while the other 55 volunteers suffered old and scarred SD. Morphological characteristics and anatomical distribution of the SD were evaluated by a trained expert. Contrast, entropy and anisotropy of SD were obtained from cross-polarized images and skin glossiness was computed from parallel and cross-polarised images. Spectrocolorimetric data were used to calculate colour and estimate chromophores concentration in SD and in adjacent normal skin.

Results: $98.2 \%$ of the volunteers claimed their SD are due to pregnancy. They were mainly located on the abdomen (93.6\% of women), the thighs $(72.7 \%)$ and the hips (83.6\%). The recent SD are significantly darker $\left(\mathrm{L}^{*}\right)$ and redder $\left(\mathrm{a}^{*}\right)$ than old ones. These colour differences correlate to a higher concentration of skin chromophores in recent SD. Texture contrast is also more important in recent SD but old SD are brighter while there in no differences in skin texture complexity nor in the directional properties between recent and old SD.

Conclusion: The visual contrast of SD can be related to chromophore distribution (recent) or light scattering (old).

Keywords: Striae Distensae; Visual Properties; Colour; Chromophore; Texture

\section{Introduction}

Striae distensae (SD) or stretch marks are common linear skin scars accompanied by epidermal atrophy [1]. They appear during pregnancy, adolescence, obesity, weight loss, bodybuilding, cachexia or in conditions associated with extensive corticosteroid use [1-4] Areas most commonly affected are the abdomen, breasts, buttocks, hips and thighs [1,5]. Despite being of no medical importance, they are an important cosmetic concern: their occurrence can be as high as $88 \%$ of pregnant women [6] and they cause significant psychological burden to many patients [4].

At the onset, the lesions appear as erythematous and inflammatory streaks (striae rubrae), oriented perpendicular to the direction of skin tension which, over months to year, mature into striae alba: atrophic, wrinkled, hypopigmented and permanent scars [7-9]. Even if the exact cause remains unclear, they would arise from a combination of hormonal factors and mechanical stretching due to rapid tissue expansion [10]. This expansion results in the reduction, thinning and disorganisation of the elastic fibre network due to elastolysis mediated by infiltrating mast cells and macrophages [11-13]. At early stages, SD formation also involve oedema in the dermis whilst striae albae are less vascularised [14].

Despite the advances made in the characterization of SD at the molecular level, their objective clinical grading by an easy to use, reproducible, and non-invasive methods is still a challenge [15]. Therefore, the objective of this study is to better characterize the biophysical properties of recent versus old SD using objective noninvasive methods. We also decided to focus our study on Chinese women, a population for which only few data are available.

\section{Material and Methods}

\section{Population}

A cohort of 110 Chinese women from the city of Wuhan and its surrounding (Hubei province, Central China) was recruited after signing a written informed consent. The age of the volunteers was 
ranging between 21 and 45 years old. Fifty-five of them (mean age $=28.5$ years old) suffered recent (less than a year in $95 \%$ of the cases) and inflamed SD while the other 55 volunteers (mean age = 35.9 years old) presented old (more than a year-old in $85 \%$ of the cases) and scarred SD.

\section{Clinical scoring of SD}

Morphological characteristics and anatomical distribution of the SD were evaluated by a trained expert. The study focused on the abdomen, the breasts, the thighs, the hips and the arms where the number, the length and the width of SD were determined. A 109 items questionnaire was also used to identify the origin of the SD and their influence on self-appreciation of the volunteers' body.

\section{Visual and spectrocolorimetric analysis of SD}

The visual properties were investigated with a digital camera system using controlled polarised light conditions (Nomad, Newtone Technologies, France). Texture of SD was evaluated in term of roughness, regularity and isotropy. Roughness and regularity are quantified using, respectively, the contrast and entropy parameters described by Haralick [16]. These parameters are obtained by the computation of co-occurrence matrix. This statistical tool measures the distribution of grey levels in the image, or in a given region of interest, and highlights the frequency and regularity of a colour to detect a possible pattern. The contrast, which measures local variations of grey levels is defined according to the following formula:

$$
\text { Contrast }=\sum_{i, j=0}^{N-1} p_{i, j} \cdot(i-j)^{2}
$$

Where, $\mathrm{Pi}, \mathrm{j}$ is the co-occuring value of a pair of pixels with specific values ( $i$ and $j$ ) and in a specified spatial relationship occur in an image; and where $\mathrm{N}$ the number of rows (i) and columns ( $\mathrm{j}$ ) of the co-occurrence matrix. With this formula, contrast decreases when the texture becomes smoother. It is equal to 0 when all image intensities are identical.

Entropy reflects the complexity of texture. It decreases when the texture becomes more regular and is defined as follow:

$$
\text { Entropy }=\sum_{i, j=0}^{N-1} p_{i, j} \cdot\left(-\ln \left(P_{i, j}\right)\right)
$$

Skin texture anisotropy was measured to determine the homogeneity in the orientation of the skin texture at the level of SD. For this purpose, a tensor image is computed from the cross-polarized image. This image allows visualization of skin lines orientation from a 2D image. The anisotropic coefficient is quantified according to Zahouani et al. [17]:

$$
A . I .=\frac{1}{2} \frac{\sum_{i=0}^{N-1}\left|R_{i}-S / N\right|}{S-S / N} * 100
$$

To calculate specular glossiness, a gloss map was generated by compensating parallel and cross polarized images exposition and computing the difference between them. Glossy pixels were extracted from the gloss map using an automatic threshold method [18] (Figure 1). Their value was averaged to obtain the specular glossiness value, value that increases when the skin is glossier. Finally, reflexion spectra of SD and adjacent normal skin were acquired using a CM 700d spectrocolorimeter (Konica Minolta Sensing, Japan). Spectra were used to calculate the $\mathrm{L}^{*}, \mathrm{a}^{*}$, $\mathrm{b}^{*}$ colour parameters [ 19 and the $\Delta E$ colour difference parameter [19]. They were also used to calculate oxy , deoxy hemoglobin and melanin concentrations [20] in SD and to compare to those of adjacent skin.
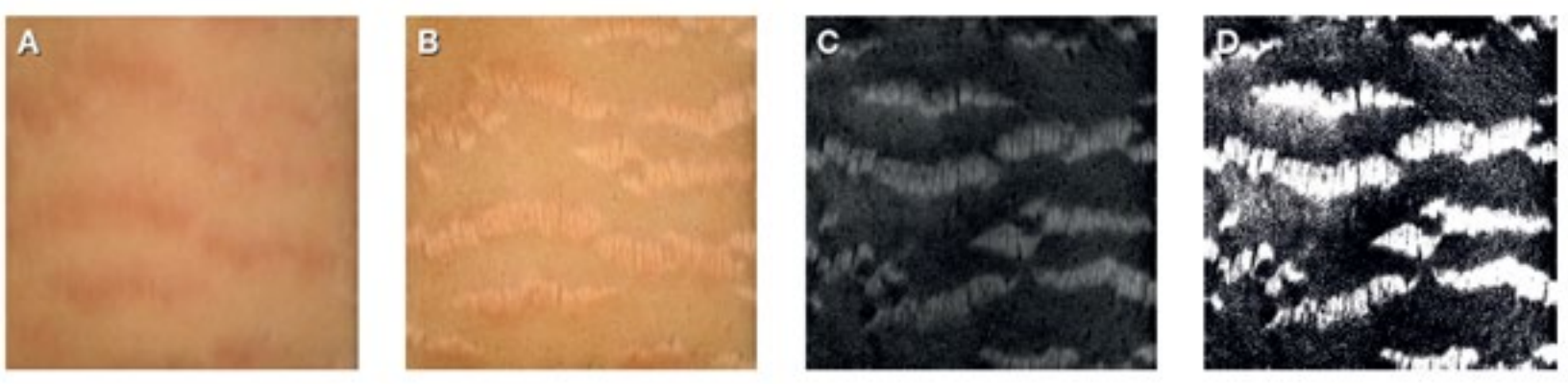

Figure 1: Illustration of specular glossiness calculation. From left to right (A) SD under cross-polarized image, (B) SD under parallelpolarized image, (B) gloss map and (D) glossy pixels after segmentation.

\section{Statistical analysis}

Data are expressed as mean \pm standard deviation. Statistical comparisons were performed using paired or unpaired Student's t-test (significance level at $\mathrm{a}=0.05$ ) following confirmation of normality of the data distribution using the Anderson-Darling test.
Results

\section{The cohort recruited shows "normal" clinical scoring of SD}

The SD of the 110 Chinese women volunteers were mainly located on the abdomen ( $93.6 \%$ of the women), the hips (83.6\%) 
and the thighs $(72.7 \%)$. Only $6.4 \%$ of the women presented SD on the breasts and $3.6 \%$ on the arms. For $98.2 \%$ of the volunteers, SD were due to pregnancy. Only one woman claimed they were due to body development and another one to weight gain.

Table 1: Clinical quotation of SD. Number, length $(\mathrm{mm})$ and width $(\mathrm{mm})$ of $\mathrm{SD}$ are given as mean \pm standard deviation when SD are presents.

\begin{tabular}{|c|c|c|c|c|c|}
\hline & Region of the body & $\begin{array}{c}\text { Percentage of women } \\
\text { with SD }\end{array}$ & Number of SD & Length of SD & Width of SD \\
\hline All volunteers & Abdomen & 93.6 & $4.2 \pm 2.1$ & $2.8 \pm 1.4$ & $0.3 \pm 0.1$ \\
\hline & Hips & 83.6 & $2.6 \pm 1.5$ & $3.1 \pm 1.8$ & $0.3 \pm 0.2$ \\
\hline & Thighs & 72.7 & $2.3 \pm 1.3$ & $2.8 \pm 1.7$ & $0.2 \pm 0.1$ \\
\hline & Breasts & 36.4 & $2.3 \pm 0.7$ & $2.2 \pm 0.6$ & $0.3 \pm 0.1$ \\
\hline & Arms & 3.6 & $1.3 \pm 0.2$ & $2.3 \pm 0.5$ & $0.2 \pm 0.0$ \\
\hline Recent SD group & Abdomen & 92.7 & $4.1 \pm 1.8$ & $2.7 \pm 1.3$ & $0.3 \pm 0.1$ \\
\hline & Hips & 81.8 & $2.6 \pm 1.3$ & $3.3 \pm 1.9$ & $0.4 \pm 0.1$ \\
\hline & Thighs & 61.8 & $1.9 \pm 1.0$ & $2.3 \pm 0.8$ & $0.2 \pm 0.1$ \\
\hline & Breasts & 7.3 & $2.8 \pm 1.7$ & $2.0 \pm 0.6$ & $0.3 \pm 0.1$ \\
\hline & Arms & 3.6 & $1.5 \pm 0.7$ & $2.3 \pm 1.1$ & $0.2 \pm 0.0$ \\
\hline & Abdomen & 94.5 & $4.3 \pm 2.0$ & $2.9 \pm 1.3$ & $0.3 \pm 0.1$ \\
\hline & Hips & 85.5 & $2.6 \pm 1.3$ & $3.0 \pm 0.9$ & $0.3 \pm 0.1$ \\
\hline & Thighs & 83.6 & $2.6 \pm 1.0$ & $3.2 \pm 1.5$ & $0.2 \pm 0.1$ \\
\hline & Breasts & 5.5 & $1.7 \pm 1.2$ & $2.5 \pm 0.8$ & $0.2 \pm 0.0$ \\
\hline
\end{tabular}

Clinical grading (Table 1) reveals no differences between women harbouring recent or old SD: the average number of SD on each zone is similar as well as the length or the width of SD. Finally, self-assessment of the impact of SD on appreciation of the volunteers' body confirms their negative influence: $58 \%$ of the volunteers claimed having a rather negative image of their body, SD bother $68 \%$ of them for the image they have of themselves and $81 \%$ of them for the image they present to others. Finally, SD influences the way $65 \%$ of the volunteers dress.

\section{While old SD have similar colour than adjacent normal skin, recent SD are darker and redder}

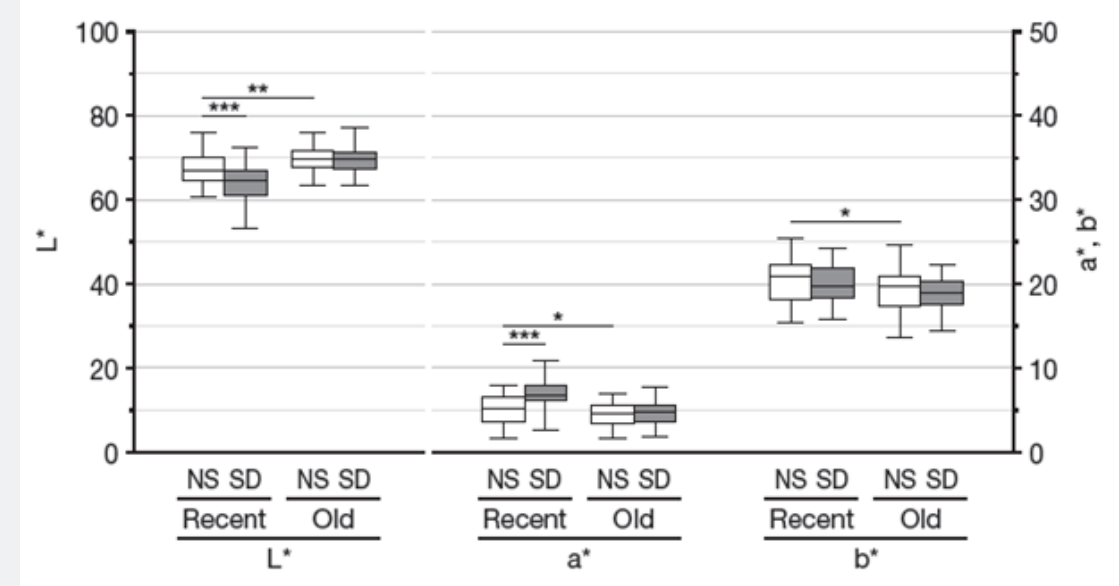

Figure 2: Box plot of the $L^{*}, a^{*}, b^{*}$ colour parameters of SD (in grey) and adjacent normal skin (NS, in white) in the recent and old SD groups. Significance is the results of paired Student's t-test between data from SD and those of adjacent normal skin with ${ }^{*}=p<0.05,{ }^{* *}=$ $p<0.001$ and ${ }^{* *}=p<0.0001$ 
Initial comparison of the skin's L*, a*, b* parameters obtained by spectrocolorimetric analysis show that the two groups of women have normal skin with significantly different colour $L^{*}, a^{*}$ and $\mathrm{b}^{*}$ parameters (Figure $2-\Delta \mathrm{E}=2.65$ ). Therefore, our analysis focused on the colour difference between SD and adjacent normal skin within each group. This analysis shows that while there is no significant difference in the $\mathrm{L}^{*}, \mathrm{a}^{*}, \mathrm{~b}^{*}$ parameters between old SD and adjacent normal skin, there are differences between recent SD and adjacent normal skin (Figure 2). Recent SD are 5.4\% darker $(\mathrm{p}<0.0001)$ and $35.3 \%$ redder $(\mathrm{p}<0.0001)$ while there is no significant difference in the yellow-blue $b^{*}$ parameter $(p=0,099)$.

Oxy-, deoxy-hemoglobin and melanin concentrations are higher in SD than in normal skin, but the difference is more important and more significant in recent SD

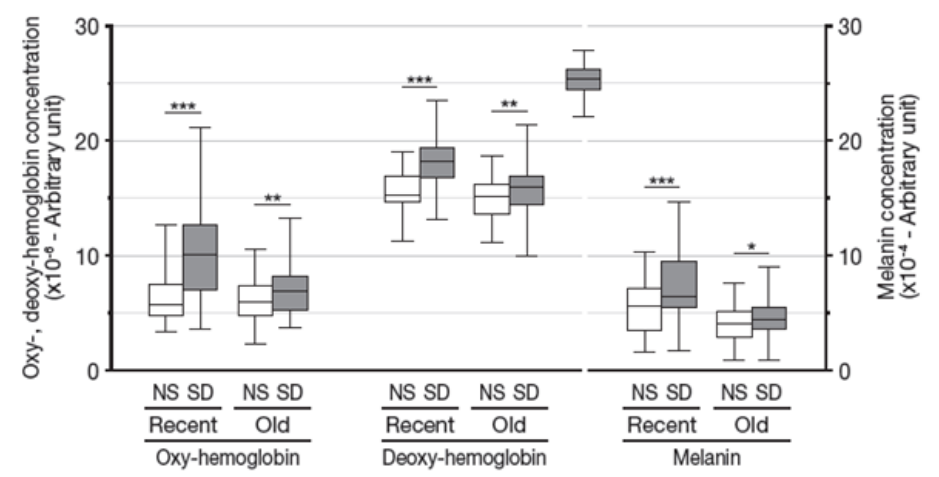

Figure 3: Box plot of the oxy, deoxy hemoglobin and melanin concentrations in SD (in grey) and adjacent normal skin (NS, in white) in the recent and old SD groups. Significance is the results of paired Student's t-test between data from SD and those of adjacent normal skin with ${ }^{*}=p<0.05,{ }^{* *}=p<0.001$ and ${ }^{* * *}=p<0.0001$

To gain possible insight in the underlying colour differences between recent and old SD we used the spectral data acquired with the spectrocolorimeter to compute the concentration of oxy-, deoxy-hemoglobin and melanin. Again, to avoid effect due to normal skin colour variation between the two groups, the analysis focused on the comparison between SD and adjacent normal skin. Results show (Figure 3) that the amount of oxy-, deoxy- hemoglobin and melanin is respectively $12.1 \%(p=0.0018), 5.7 \%$ $(p=0.0005)$ and $8.6 \%(p=0.029)$ higher in old SD than in adjacent normal skin. For recent SD, the differences are more pronounced and show higher significance with $61.2 \%(\mathrm{p}<0.0001)$ more oxyhemoglobin in SD than in adjacent normal skin, $16.0 \%(\mathrm{p}<0.0001)$ more deoxy-hemoglobin and $34.3 \%(p<0.0001)$ more melanin.

\section{Recent and old SD differ in their brightness and grain but not in their texture}

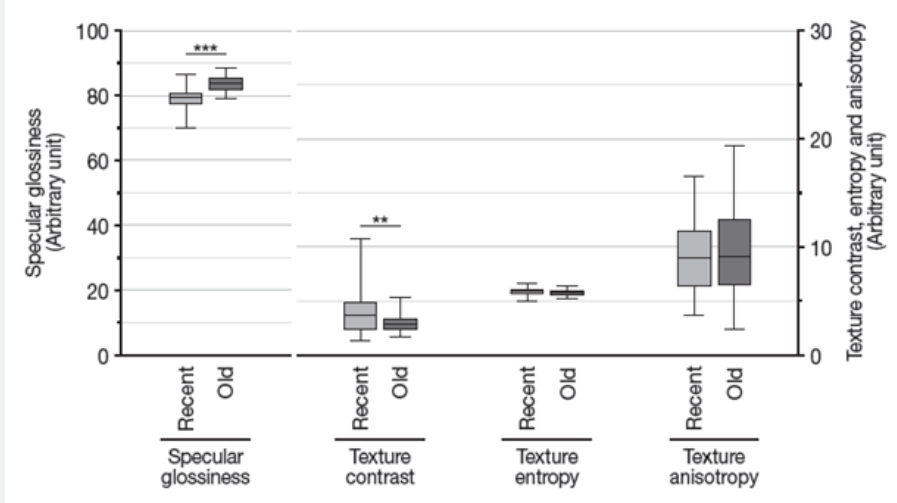

Figure 4: Box plot of the specular glossiness and of the texture contrast, entropy and anisotropy in SD of the recent (light grey) and old (dark grey) SD groups. Significance is the results of unpaired Student's t-test between data from recent SD and those of old SD with ${ }^{* *}=$ $p<0.001$ and ${ }^{* * *}=p<0.0001$ 
We also studied the texture differences that exist between recent and old SD using pictures taken under polarised light. Results (Figure 4) show that the specular glossiness is higher in old SD than in recent SD $(+5.8 \%, \mathrm{p}<0.0001)$ while the texture contrast is more important in recent SD compared to old ones $(+33.2 \%, p<0.0001)$. In other words, if old SD reflect more light than recent SD, the skin micro-relief of SD is more important when they are recent. In addition, texture entropy and anisotropy are similar in both recent and old SD, namely there is no significant difference in skin texture complexity nor in the directional properties between recent and old SD.

\section{Discussion}

Since their first histological description [21], SD have been described in many ethnic groups and where shown to have similar clinical appearance. Still, their colour can vary $[14,22]$. On white colour skin, recent SD are generally erythematous (striae rubrae) and then turn white (striae albae). They can also be blackish in dark-pigmented populations (striae nigrae) or bluish in case of prolonged corticotherapy (striae caeruleae). Therefore, we were interested in better characterising the appearance of SD in the Chinese population for which little is known.

To circumvent the fact that the volunteers with recent and old SD where presenting normal skin with different complexion, we focused our analysis on the comparison of SD to adjacent normal skin within each group. Results show that recent SD are slightly darker and much redder than adjacent normal skin while the colour of old SD does not differ to that of adjacent skin. The colour data of recent SD are in agreement with the increased concentration of oxy-, deoxy-hemoglobin and melanin we quantified in recent SD. This increase in skin chromophore is also detected in old SD but to a lower and less significant extend which probably explains why it is not detected as a colour difference.

The results we obtained for the colour and chromophore content of recent SD in the Chinese population we studied are in agreement with previous studies performed on other ethnic groups which relates the initial red and erythematous appearance of recent SD to changes in microvasculature and melanocyte activity $[14,22,23]$. We also show that, similarly to a Caucasian population, old SD from Chinese women still present a slight accumulation of melanin [24]. Conversely, the increase of oxy-, deoxy-haemoglobin we show in old SD differs from what has been obtained in a Caucasian population where such an increase was not detected [24]. Indeed, old SD are generally described as being lighter than surrounding skin [14] which most probably relates to differences in methodology and the higher specular glossiness of old SD.

This high specular glossiness of old SD indicates a higher skin glossiness, due to less variation in skin micro-relief, than in recent SD. It also correlates to the lower texture contrast we found in old $\mathrm{SD}$ compared to recent SD. Both results clearly relate to changes in skin structure. Indeed, SD are also known to be accompanied by several microstructural changes. They are characterized by gradual atrophy of the epidermis, including loss of rete ridges [25]. The mid-dermis undergoes elastolysis as evidenced by mast cell degranulation and stimulation of macrophages [12]. The elastic fibre network breaks down, collagen fibres thicken, become more densely packed and arranged in a parallel pattern $[13,15]$. The fact that we do not observed any difference in texture entropy or anisotropy suggest that, at the macroscopic level, underlying changes in skin structure occurring in recent SD remains in old $\mathrm{SD}$. Still these differences are more visible, producing more microrelief to skin texture, in recent SD.

\section{Conclusion}

If some differences might exist in populations with different skin complexion, especially when darker, we show that, similarly to the Caucasian population, the visual characteristics of recent SD in Chinese women relates to colour. Darker and redder than adjacent normal skin, the colour difference relates to an increased concentration of oxy-, deoxy-hemoglobin and melanin. If old SD also show higher concentration of chromophores than normal skin, they show no colour difference and are characterised by their glossiness that relates to changes in skin structure.

\section{Acknowledgement}

The authors thank Claire Sylvain / Pr Wenyao Yu from COSderma for data acquisition and Pierre Seroul / Matthieu Jomier from Newtone Technologies for the analysis of visual data. They also wish to thank Dr Philippe Crouzet, Estium-Concept, for scientific writing services.

\section{References}

1. Cho S, Park ES, Lee DH, Li K, Chung JH (2006) Clinical features and risk factors for striae distensae in Korean adolescents. J Eur Acad Dermatol Venereol 20(9): 1108-1113.

2. Henry F, Pierard-Franchimont C, Pans A, Pierard GE (1997) Striae distensae of pregnancy. An in vivo biomechanical evaluation. Int J Dermatol 36(7): 506-508.

3. Neve S, Kirtschig G (2006) Elastotic striae associated with striae distensae after application of very potent topical corticosteroids. Clin Exp Dermatol 31(3): 461-462.

4. Atwal GS, Manku LK, Griffiths CE, Polson DW (2006) Striae gravidarum in primiparae. Br J Dermatol 155(5): 965-969.

5. Salter SA, Kimball AB (2006) Striae gravidarum. Clin Dermatol 24(2): 97-100.

6. Ghasemi A, Gorouhi F, Rashighi-Firoozabadi M, Jafarian S, Firooz A (2007) Striae gravidarum: associated factors. J Eur Acad Dermatol Venereol 21(6): 743-746.

7. Elson ML (1994) Topical tretinoin in the treatment of striae distensae and in the promotion of wound healing: a review. J Dermatol Treat 5(3): 163-165.

8. Kang S (1998) Topical tretinoin therapy for management of early striae. J Am Acad Dermatol 39 (2 pt 3): S90-92. 
9. Kim BJ, Lee DH, Kim MN, Song KY, Cho WI, et al. (2008) Fractional photothermolysis for the treatment of striae distensae in Asian skin. Am J Clin Dermatol 9(1): 33-37.

10. Al Himdani S, Ud Din S, Gilmore S, Bayat A (2014) Striae distensae: a comprehensive review and evidence-based evaluation of prophylaxis and treatment. Br J Dermatol 170(3): 527-547.

11. Shuster S (1979) The cause of striae distensae. Acta Derm Venereol Suppl (Stockh) 59(85): 161-169.

12. Sheu HM, Yu HS, Chang CH (1991) Mast cell degranulation and elastolysis in the early stage of striae distensae. J Cutan Pathol 18(6): 410-416.

13. Watson RE, Parry EJ, Humphries JD, Jones CJ, Polson DW, et al. (1998) Fibrillin microfibrils are reduced in skin exhibiting striae distensae. $\mathrm{Br}$ J Dermatol 138(6): 931-937.

14. Hermanns JF, Piérard GE (2006) High-resolution epiluminescence colorimetry of striae distensae. J Eur Acad Dermatol Venereol 20(3): 282-287.

15. Gilmore SJ, Vaughan BL, Madzvamuse A, Maini PK (2012) Textural Features for Image Classification. IEEE Trans. Syst., Man, Cybern 3(6): 620-621.

16. Haralick RM, Shanmugam K, Dinstein I (1973) Textural Features for Image Classification. IEEE Trans. Syst., Man, Cybern 3(6): 620-621.

17. Zahouani H, Vargiolu R, Humbert P (1998) 3D morphology tree representation of the skin relief. A new approach of skin image characterization. 20th IFSCC Congress, Cannes, France 3: 69-79.
18. MacQueen J (1967) Some methods for classification and analysis of multivariate observations. Proc. Fifth Berkeley Symp. on Math Statist and Prob 1: 281-297.

19. (2011) Methods for Evaluating Colour Differences in Images. CIE 199:2011.

20. Stamatas GN, Zmudzka BZ, Kollias N, Beer JZ (2008) In vivo measurement of skin erythema and pigmentation: new means of implementation of diffuse reflectance spectroscopy with a commercial instrument. Br J Dermatol 159(3): 683-690.

21. Troisier E, Ménétrier P (1889) Histologie des vergetures. Ann Gynecol 31:206.

22. Piérard Franchimont C, Hermanns JF, Hermanns Lê T, Piérard GE (2005) Striae distensae in darker skin types: the influence of melanocyte mechanobiology. J Cosmet Dermatol 4(3): 174-178

23. Devillers C, Piérard Franchimont C, Schreder A, Docquier V, Piérard GE (2010)High resolution skin colorimetry, strain mapping and mechanobiology. Int J Cosmet Sci 32(4): 241-245.

24. Stamatas GN, Lopes DaCunha A, Nkengne A, Bertin C (2015) Biophysical properties of Striae Distensae evaluated in vivo using non-invasive assays. Skin Res Technol 21(2): 254-258.

25. Singh G, Kumar LP (2005) Striae distensae. Indian J Dermatol Venereol Leprol 71(5): 370-372.

\section{Your next submission with Juniper Publishers will reach you the below assets}

- Quality Editorial service

- Swift Peer Review

- Reprints availability

- E-prints Service

- Manuscript Podcast for convenient understanding

- Global attainment for your research

- Manuscript accessibility in different formats

(Pdf, E-pub, Full Text, Audio)

- Unceasing customer service

Track the below URL for one-step submission https://juniperpublishers.com/online-submission.php 